\title{
MODELLING TOOL FOR SOLVING MANUFACTURING SYSTEM DYSFUNCTION IN RUBBER SEED OIL BASED ALKYD RESIN PREPARATION
}

\author{
T. B. Adeleke ${ }^{1,{ }^{*},}$, S. I. Ukwuaba ${ }^{2}$ and P. O. Akpaka ${ }^{3}$ \\ 1, DePartment of Production Engineering, University of Benin, Benin City, Edo State, NigeriA. \\ 2, Department of Mechanical Engineering, Pertoleum Training Institute, EFFurun, Delta State, Nigeria \\ 3, RUBber RESEARCH INSTITUTE OF NigeRIA, IYANOMO, P.M.B 1049, BENIN City, Edo STATE, NiGERIA \\ E-mail addresses: 1tundebasit123@gmail.com,2 ukwuabasamuel@gmail.com, 3akpakaphilip@gmail.com
}

\begin{abstract}
Variability in production output, low quality, wastes, and downtimes are serious production problems which manufacturers of alkyd resin product are facing and it invariably affect manufacturers' economic performance and the nation economic growth which are often caused by differences in process temperatures and length of the resin. There is a strong incentive in controlling the end of the batch product property values so as to minimize the variability in product quality. This study seeks to investigate the relationship among variables capable of affecting the production process output of rubber seed oil based alkyd resin. A random survey of relevant literature was conducted to gather relevant information required that are capable of causing a dysfunction in the manufacturing process of rubber seed oil based alkyd resin for use in anti-corrosion paint application. The sensitivity and versatile applicability of opinion discrimination analysis as an off-line tool for dealing with these types of problems was apt. Our result showed that there is a strong relationship between temperature, catalyst, absence of catalyst, length of resin, acidic content, water resistance which can be manipulated to appreciably reduce product degradation and control process variability. Moreover, we showed that opinion discrimination analysis modelling tool can be used to determine the need to understand production process approach for alkyd resin. The study has ably demonstrated that opinion discrimination analytical modelling tool is very effective in fault diagnosis.
\end{abstract}

Keywords: Opinion discrimination analysis, discriminative power, manufacturing system dysfunction, rubber seed oil, alkyd resin

\section{INTRODUCTION}

Improving product quality is the most preoccupation of industrial managers and engineers, due to the stringent industrial specification that today's alkyd resin must meet, the need for fine tuning the factors that causes variabilities is more acute than ever. Controlling the end of the batch product property values so as to minimize the variability in product quality in order to reduce wastes in production output, low quality outputs, poor equipment designs and production process equipment downtimes among others appear to be some of the major problems which manufacturers of rubber seed oil based alkyd resin and biodiesel product usually encounter in the cause of production [1]. Essentially, [2] also stated that the lack and the increasing prices of raw materials and energy require today a decrease of production costs for large technical processes and reducing their variability will also help in this regard. There is a strong incentive in controlling the end of the batch product property values so as to minimize the variability in product quality.

Typically, the manufacturing of a batch according to [3] and [4] involves charging ingredients to the vessel, processing them under controlled conditions, and discharging the final product. A batch operation is considered successful if the values of the process variables remain within acceptable limits while following the recipe prescribed for the process, resulting in a uniform, high-quality product and in this case high quality alkyd resin product from rubber seed oil [5].

The cause of low quality output and waste is traceable to the nature of the finished product or lack of proper maintenance of the process line for the production process [6]. Wastes and low quality product are serious production problems which manufacturers of product 
are facing and it invariably affect manufacturers' economic performance and the nation economic growth in general, it is essential therefore that the causes be researched with a view to eliminating them.

The traditional approach of adopting specific routine maintenance policy coupled with adjustments to controllers are no longer considered cost effective in today's modern technology besides the fact that it entails holding more workforce to maintain such traditional system. This was the view of [7] and [8].

In fact, [9] opined that continuing processes control in manufacturing systems becomes more and more necessary. Particularly, innovative monitoring and control techniques of the batch process operations are strongly needed in the process control field to increase product quality.

The opinion discrimination analysis or opinion discrimination analytical (ODA) modelling approach is predictive and innovative by nature in the sense that it foresees the imminence of process capability deterioration as well as the magnitude or degree of such dysfunction and based on such information adequate corrective action could then be taken. Literature reviewed in [10] has lucidly confirmed the versatility and applicability of opinion discrimination analytical modelling approach in detecting product failures generally. Authors' belief in [11] and [12] points to the fact that opinion discrimination analytical modelling approach is relevant in enhancing product quality, reduction of wastes, equipment and production system's management. The balance of literature on production system appears to offer little on opinion discrimination analytical modelling approach applications. Evidently the current research is an attempt to create a breach in this knowledge frontier. This study therefore is to demonstrate the plausibility of applying opinion discrimination analytical modelling approach or tool in dealing with the problem capable of causing a dysfunction in the manufacturing process of rubber seed oil based alkyd resin for use in anticorrosion paint manufacture.

\section{METHODOLOGY}

The research method entails the application of survey method to gather relevant information required to build appropriate data matrix that are capable of causing a dysfunction in the manufacturing process of rubber seed oil based alkyd resin for use in anticorrosion paint application. To achieve this end, extensive literature survey was carried out to articulate enough data. There were 29 variables (scale items) selected from the literature search to extensively cover factors causing manufacturing dysfunction in the production process of alkyd resin from rubber seed oil. The questions were carefully crafted to agitate curiosity of the respondents to respond positively to each of the 29 scale items/ variables.

Rensis Likert's 5-point attitudinal scale (5-Strongly Agreed, 4-Agreed, 3-Undecided, 2-Disagree, 1-Strongly disagree) was used in dimensioning the respondent's responses, which were recorded in descending order of rating, were captured in a $100 \times 29$ data matrix and subsequently analysed with a statistical tool known as Opinion Discrimination Analysis (ODA) tool / model to obtain the discriminative powers (DP). The DP values were plotted as bar chart and interpretations rendered.

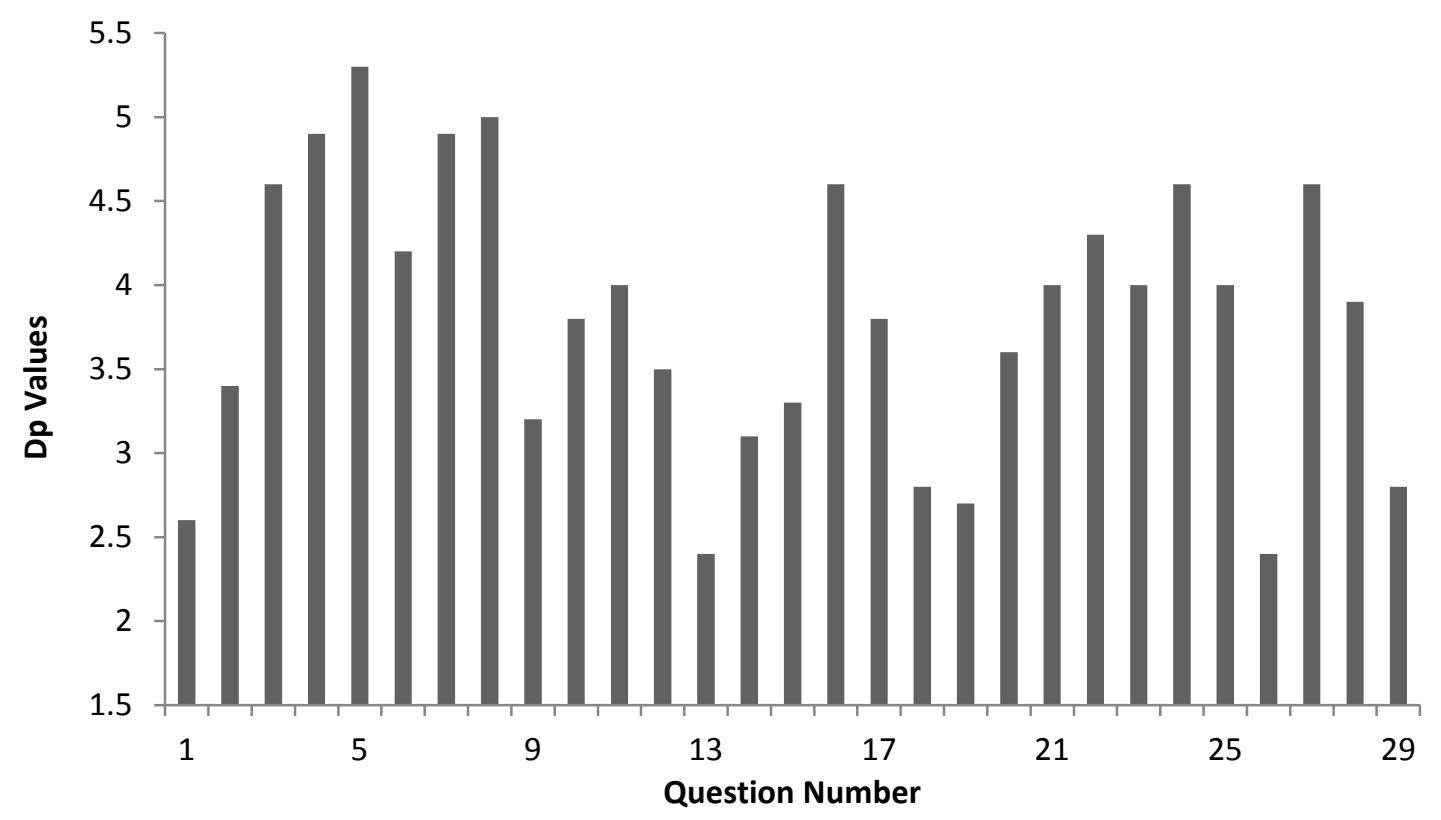

Figure 1: Dp Values of the factors affecting Alkyd Resin Production 
They are segmented as follows:

(i) Lower bandwidth: $2.4<D P \leq 3.0$ In this regime, the respondents are in total agreement on the issue considered. In other words there is consensuality.

(ii) Middle bandwidth: $3.1<\mathrm{DP} \leq 4.0$ In this group, the respondents are fairly in agreement on the subject matter.

Upper bandwidth: DP > 4.0 In this category, the respondents are weakly in agreement with what was put forth.The figure above represents the influence of the magnitude of the factors as it affects the production process.

\section{RESULTS AND DISCUSSION}

The DP values in Table 1 are low indicating that there is high level of agreement among respondents that these variables can affect the preparation process for alkyd resin production.

Table 1: Lower bandwidth DP values of variables that affect the production process of rubber seed oil based alkyd resin preparation.

\begin{tabular}{lll}
\hline $\begin{array}{l}\text { Variable } \\
\text { Number }\end{array}$ & Description & DP Value \\
\hline 1 & Catalyst & 2.6 \\
13 & Absence of catalyst & 2.4 \\
18 & Temperature & 2.8 \\
19 & Water resistance & 2.7 \\
26 & Length of resin & 2.4 \\
29 & Acidic content & 2.8 \\
\hline
\end{tabular}

Table 2: Middle bandwidth DP values of variables that affect the production process of rubber seed oil based alkyd resin preparation.

\begin{tabular}{lll}
\hline $\begin{array}{l}\text { Variable } \\
\text { Number }\end{array}$ & Description & DP Value \\
\hline 2 & Excellent odour & 3.4 \\
9 & Gloss & 3.2 \\
10 & Fast drying & 3.8 \\
11 & Film hardness & 4.0 \\
12 & Chemical resistance & 3.5 \\
14 & Environmental impact & 3.1 \\
15 & Bio-stability of alkyd & 3.3 \\
17 & Presence of oxidizing agent & 3.8 \\
20 & Resin thickness & 3.6 \\
21 & Universal availability & 4.0 \\
23 & Polyol & 4.0 \\
25 & Iodine value & 4.0 \\
28 & Gloss retention & 3.9 \\
\hline
\end{tabular}

In Table 2, the respondents are fairly in agreement with certain attributions made concerning these variables.
Any decision reached about this cluster is therefore considered fairly conclusive. We can say that the DP values resulting is middling signifying inconclusiveness or is up the air or unresolved or in otherwords middle of the road difference.

Table 3: Upper bandwidth DP values of variables that affect the production process of rubber seed oil based alkyd resin preparation.

\begin{tabular}{lll}
\hline $\begin{array}{l}\text { Variable } \\
\text { Number }\end{array}$ & \multirow{2}{*}{ Description } & $\begin{array}{l}\text { DP } \\
\text { Value }\end{array}$ \\
\hline 3 & Heat bleach ability & 4.6 \\
4 & Viscosity & 4.9 \\
5 & Colour & 5.3 \\
6 & Percentage yield & 4.2 \\
7 & Flexibility & 4.9 \\
8 & Durability & 5.0 \\
16 & Storage property & 4.6 \\
22 & Low cost & 4.3 \\
24 & Esterification & 4.6 \\
27 & Resistance to abrasion & 4.6 \\
\hline
\end{tabular}

In Table 3 the DP values are high, the variables clustered therein are relatively controversial, as the respondents are weakly in agreement with the attributions made concerning such variables. There is a case of controvertibility.

At the onset it was claimed that opinion discrimination analytical modelling approach or tool can deal with the problem capable of causing a dysfunction in the manufacturing process of rubber seed oil based alkyd resin for use in anti-corrosion paint manufacture and biodiesel.

The DP-values obtained have enabled us to appreciate the main factors to blame for manufacturing dysfunction in the manufacturing process of rubber seed oil based alkyd resin for use in anti-corrosion paint manufacture. In particular their relative influence is indicative of the magnitude of the DP-values. This is also a manager's guide to action.

In summary, the opinion discrimination analytical modelling approach or tool developed using DP-values, have been helpful in dealing with manufacturing dysfunction in the manufacturing process of rubber seed oil based alkyd resin common in small and medium scale enterprises especially in developing countries where manufacturing functions are stymied by economic depression. Thus, the use of the opinion discrimination analytical modelling approach or tool as an aid in the manufacturing sector would likely engender economic growth and development in the industrial sector. 


\section{CONCLUSION}

Several factors work conjointly to affect manufacturing dysfunction. The opinion discrimination analytical modelling approach or tool proposed is effective in dealing with the problem of process variability and degraded output. Manufacturing industries of rubber seed based alkyd resin are in concordance that these variables contribute to low quality of outputs. This is evidenced by the low DP-values obtained. This empirical evidence is supportive to the objectives of the study. Also opinion discrimination analytical modelling approach or tool has been shown to possess inherent properties for predicting imminence of process capability deterioration. Finally, the theory underpinning the discriminative power index is also developed and demonstrated.

\section{REFERENCES}

[1] Igboanugo A. C. and Nwobi-Okoye C. C., "Transfer Function Modelling as a Tool for Solving Manufacturing System Dysfunction" Research journal of Applied Sciences, Engineering and Technology 4(23): 4948-4953, Maxwell Scientific Organization, 2012.

[2] Igboanugo, A. C. and C. C. Nwobi-Okoye "Production process capability measurement and quality control using transfer functions. Journal of the Nigerian Association of Mathematical Physics, 19: 453-464, 2011.

[3] Ogunnaike, B. A., "On-line Modeling and Predictive Control of an Industrial Terpolymerization Reactor", International Journal of Control, 59, pp.711, 1994.

[4] Enrique A. M., "Monte Carlo Simulation to Propose Improvements of an Alkyd Resin Process" Proceedings of the 7th WSEAS International Conference on Simulation, Modelling and
Optimization, Beijing, China, September 15-17, 2007.

[5] Jaleel V. A and Christos G. N, "Nonlinear Model Predictive Control of End-Use Properties in Batch Reactors" Chemical Process Modeling and Control Research Center and Dept. of Chemical Engineering, Lehigh University, Bethlehem, PA 18015, Vol. 48, No. 91994.

[6] Wafik H., Ines M. and Riadh K., "Integration of Statistical and Engineering Process Control in a Batch Processes Monitoring: Case of Alkyd Polymerization Reactor" International Journal of Control and Automation Vol. 5, No. 1.2012.

[7] Iyayi A. F., Akpaka P. O. and kpeoyibo U. U, "Rubber seed processing for value-added latex production in Nigeria" African Journal of Agricultural Research, vol. 3 (7), pp. 505-509, 2008.

[8] Aigbodion A. I., Pillai C. K. S. "Preparation, analysis and applications of rubber seed oil and its derivatives in surface coatings" Progress in Organic Coatings Vol. 38 pp.187-192, 2000.

[9] Ikhuoria, E. U., Aigbodion, A. I. and Okieimen, F. E. Enhancing the quality of alkyd resins using methyl esters of rubber seed oil. Tropical Journal of Pharmaceutical Research, 3 (1), 311-317, 2004,

[10] M. Alam, D. Akram, E. Sharmin, F. Zafar, S. Ahmad, "Vegetable oil based eco-friendly coating materials: a review article" Arabian J. Chem. 7, 469-479, 2014.

[11] Oil and Colour Chemist's Association of Australia, Surface coatings, vol. 1, Raw Materials and Their Uses, Chapman \& Hall, London, p. 1, 1981.

[12] Nwankwo B. A., Aigbekaen E. O., Sagay G. A., "Estimates of natural seed production in Nigeria. In: E. E. Enabor (Ed.), Industrial Utilisation of Natural Rubber (Hevea brasiliensis), Seed, Latex and Wood". Rubber Research institute of Nigeria, Benin City, p. 78. 1986. 